\title{
Chemo- and stereoselective reduction of enaminones for the preparation of biologically active compounds
}

\author{
Gianni Palmieri,* Cristina Cimarelli \\ Dipartimento di Scienze Chimiche, v. S. Agostino 1, 62032 - Camerino (Italy) \\ E-mail: gianni.palmieri@unicam.it
}

Dedicated to Prof. Giuseppe Bartoli on the occasion of his $65^{\text {th }}$ birthday

\begin{abstract}
The chemistry of the preparation of $\beta$-enamino ketones and $\beta$-enamino esters and their use as useful starting materials in reductive procedures for the preparation of biologically active natural products is described.

Enaminones are very stable compounds and can be easily prepared, starting from cheap and easily available starting materials. Therefore they constitute also excellent starting materials in organic synthesis. Several chemo- and regioselective methodologies for their preparation have been developed also recently. The possibility to use enantiopure chiral amines for the preparation of enamino ketones and enamino esters makes available useful starting materials for the preparation of enantiopure biologically active compounds. Moreover, it is possible to obtain more complex enaminones by regio- and stereoselective functionalization of the more accessible ones.

Recently numerous methodologies for the chemo- and stereoselective reduction of enaminones have been developed, that constitute useful alternative pathways to the numerous literature procedures for the preparation of $\gamma$-amino alcohols, $\beta$-amino acids, aminoalkyl phenols and their derivatives. $\gamma$-Aminoalcohols and aminoalkylphenols are a class of very stable compounds that find useful applications in asymmetric catalysis as chelant for the preparation of chiral enantiopure metallic catalysts.
\end{abstract}

Keywords: Enaminones, $\beta$-enamino ketones, $\beta$-enamino esters, reduction, $\gamma$-amino alcohols, $\beta$ amino esters

\section{Contents}

1. Introduction

2. Synthesis of enaminones 


\subsection{Condensation \\ 2.2 Imines as precursors for $\beta$-enamino ketones and $\beta$-enamino esters \\ 2.3 Other methods}

3. Functionalization of enaminones

3.1 Regio- and stereoselective alkylation of enaminones

3.2 Other functionalizations

4. Reductions

4.1 Introduction

4.2 Chemo- and stereoselective reductions

4.2.1 Reduction of $\beta$-enamino ketones to $\gamma$-amino alcohols

4.2.2 Reduction of $\beta$-enamino esters to $\beta$-amino esters and $\beta$-aminoacids

4.2.3 Reduction of imidoyl phenols to $o$-hydroxybenzylamines

4.3 Addition reduction one-pot procedures

5. Applications of $\beta$-enamino esters reduction to the synthesis of biologically active compounds

6. Conclusions

7. References

\section{Introduction}

The term enaminones is related to compounds that contain the conjugate system described in Scheme 1 and Figure 1.<smiles>[R]C(=O)C([R])=C([R])N([R7])[Z]</smiles>

$1,3 \mathrm{~A}$

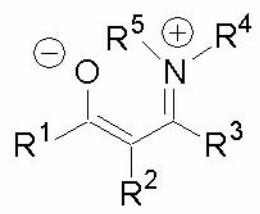

$1,3 \mathrm{~B}$

$$
\mathrm{R}^{1}=\text { alkyl, aryl, alkoxy }
$$

\section{Scheme 1}

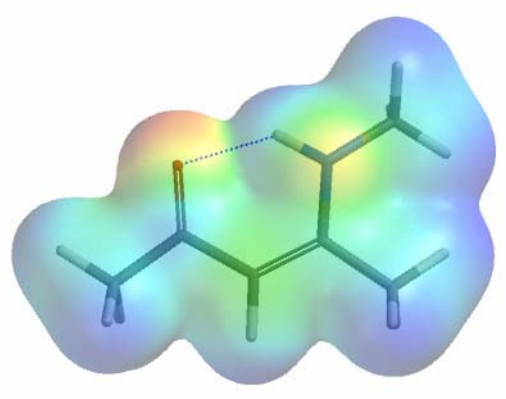

Figure 1

It is possible to distinguish enaminones in $\beta$-enamino ketones $\left(\mathbf{1}, \mathrm{R}^{1}=\right.$ alkyl, aryl $)$ and $\beta$ enamino esters $\left(3, R^{1}=\right.$ alkoxy). They are enamines of $\beta$-dicarbonyl compounds and can be considered as vinylogous amides. Four conformers of the enaminone system are possible, but when $\mathrm{R}^{5}=\mathrm{H}$ the cis $\mathbf{A}$ is the more populated and stabilized by hydrogen bond (see Figure 1).

The reactivity of these systems can be well understood examining the electronic distribution, better defined with molecular modelling. It can be calculated with quantomechanic semiempirical (PM3) or ab initio $\left(6-31 \mathrm{G}^{*}\right)$ methods and it is depicted through the distribution of 
the electrostatic potential on the electron density surface, as showed in Figures 1 and 2, by a conventional colour representation from blue to red, that represents low and high electronic charge density respectively.

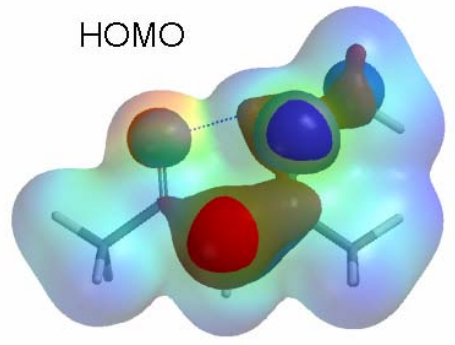

A

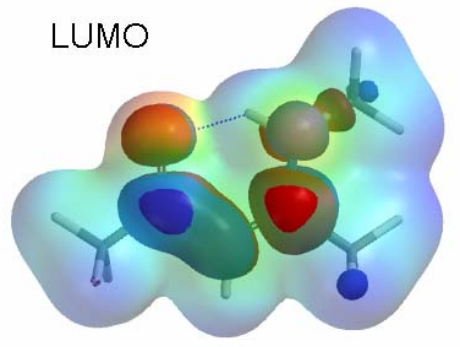

B

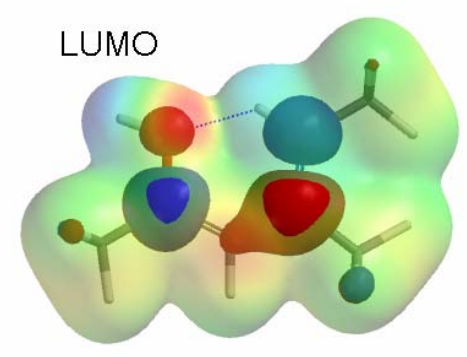

C

Figure 2. Distribution of the electrostatic potential overlapped to the HOMO (A) or LUMO (B, C) molecular orbitals, for the enaminone system $(\mathbf{A}, \mathbf{B})$ and the protonated one $(\mathbf{C})$.

The attack of electrophiles take place at the carbon atom in $\alpha$ position with respect to the carbonyl group, where there is the major distribution of HOMO orbital (A), while the reactivity towards nucleophiles is directed on the $\mathrm{sp}^{2}$ carbon atoms bonded to nitrogen or oxigen atoms, that presents the major concentration of LUMO orbital (B). In acidic medium, where the enaminone is protonated, the nucleophilic addition occurs preferentially to the iminic $\mathrm{sp}^{2}$ carbon atom as showed from the LUMO orbital $(\mathbf{C})$.

Imidoyl phenols 2 can be considered systems analogous to enaminones. Although the presence of the aromatic ring, the reactivity of the imine function is influenced by the conjugated phenolic oxygen. In this coniugated system the nucleofile addition occurs exclusively to the iminic $\mathrm{sp}^{2}$ carbon atom, as showed from the LUMO frontier orbital (E) (Figure 3).

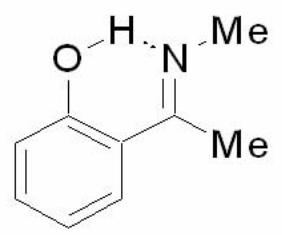

2
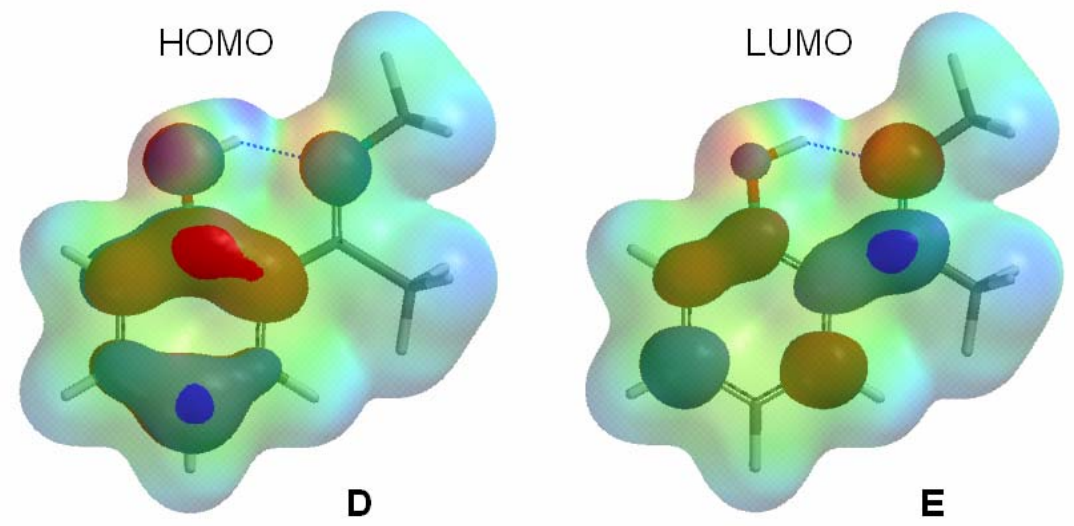

Figure 3. The distribution of the electrostatic potential and the location of their HOMO (D) or LUMO (E) molecular orbitals showed simultaneously, for the imidoyl phenol system 2. 
The chemistry of enaminones has been reviewed in the past ${ }^{1}$, and also recently. ${ }^{2}$

These classes of compounds not only possess intrinsic biological and pharmaceutical properties, but constitute also a versatile class of useful and cheap starting materials for the preparation of several classes of organic molecules, as heterocycles, ${ }^{3} \gamma$-aminoalcohols, ${ }^{4} \beta$-amino esters and $\beta$-amino acids, ${ }^{5} o$-hydroxybenzylamines. ${ }^{6}$

\section{Synthesis of enaminones}

\subsection{Condensation}

The interest in $\beta$-enamino ketones $\mathbf{1}$ and $\beta$-enamino esters $\mathbf{3}$ has stimulated a continue search for convenient methods for their synthesis.

The more straightforward way to obtain $\beta$-enamino ketones is a direct condensation of $\beta$ dicarbonyl compounds with ammonia, primary or secondary amines. As water is produced by the condensation reaction, the syntheses present in literature show a variety of methods to remove it, by use of azeotropical distillation of the solvent ${ }^{7}$ or in the presence of drying agents as montmorillonite together with microwawes $^{8}$ or ultrasounds. ${ }^{9}$ More environmental friendly methods have been developed, as solventless synthesis or reactions catalysed by tetra-Et orthosilicate, ${ }^{10} \mathrm{Zn}\left(\mathrm{ClO}_{4}\right)_{2} \cdot 6 \mathrm{H}_{2} \mathrm{O}^{11}$ or bismuth(III) trifluoroacetate ${ }^{12}$ immobilized on molten tetrabutylammonium bromide as "green" media under mild conditions and also Bi(TFA $)_{3}$ as a reusable catalyst in aqueous media. ${ }^{13}$

Analogously the preparation of $\beta$-enamino esters proceeds in the same way, but presents some drawbacks as the aminolysis of the ester function ${ }^{14}$ and in some cases the formation of the $\beta$-enamino amide byproduct. ${ }^{15}$

Another general one-step method for the preparation of enaminones, especially N,Ndimethylenaminones, is a condensation between an active methylene compound and an amide acetal ${ }^{16}$ (e.g. see). Further variation of the enaminone's amino group is possible by substitution of the dimethylamino group with various primary and secondary amines. ${ }^{17}$

On the other hand acyl phenols react so easily with primary amines to afford imidoylphenols 2 that a simple solventless methodology for their preparation has been developed. ${ }^{18}$

\subsection{Imines as precursors for $\boldsymbol{\beta}$-enamino ketones and $\boldsymbol{\beta}$-enamino esters}

The preparation of $\beta$-enamino ketones by condensation affords to an unique product only in the case of symmetrical $\beta$-dicarbonyl compounds, or when the two carbonyl groups show a very different electrophilicity towards the nucleophile amine. In the other cases the reaction is not regioselective and a mixture of regioisomer $\beta$-enaminoketones is obtained, sometimes with difficulties in their separation.

A different approach bypasses this drawback and uses as precursors useful nucleophiles as lithium imines. In fact they react with acylating agents as esters or benzoyl chloroformiate or ethyl carbonate and afford to $\beta$-enamino ketones $\mathbf{1}$ and $\beta$-enamino esters $\mathbf{3 a , b}$ in good yields. In 
this way it is possible the synthesis of asymmetrical $\beta$-enamino ketones and of a wide serie of $\beta$ enamino esters. ${ }^{15,19}$ Anyway this method presents the limitations correlated to the selective deprotonation of unsymmetrical imines and to the sensitivity of these starting materials to moisture (Scheme 2).
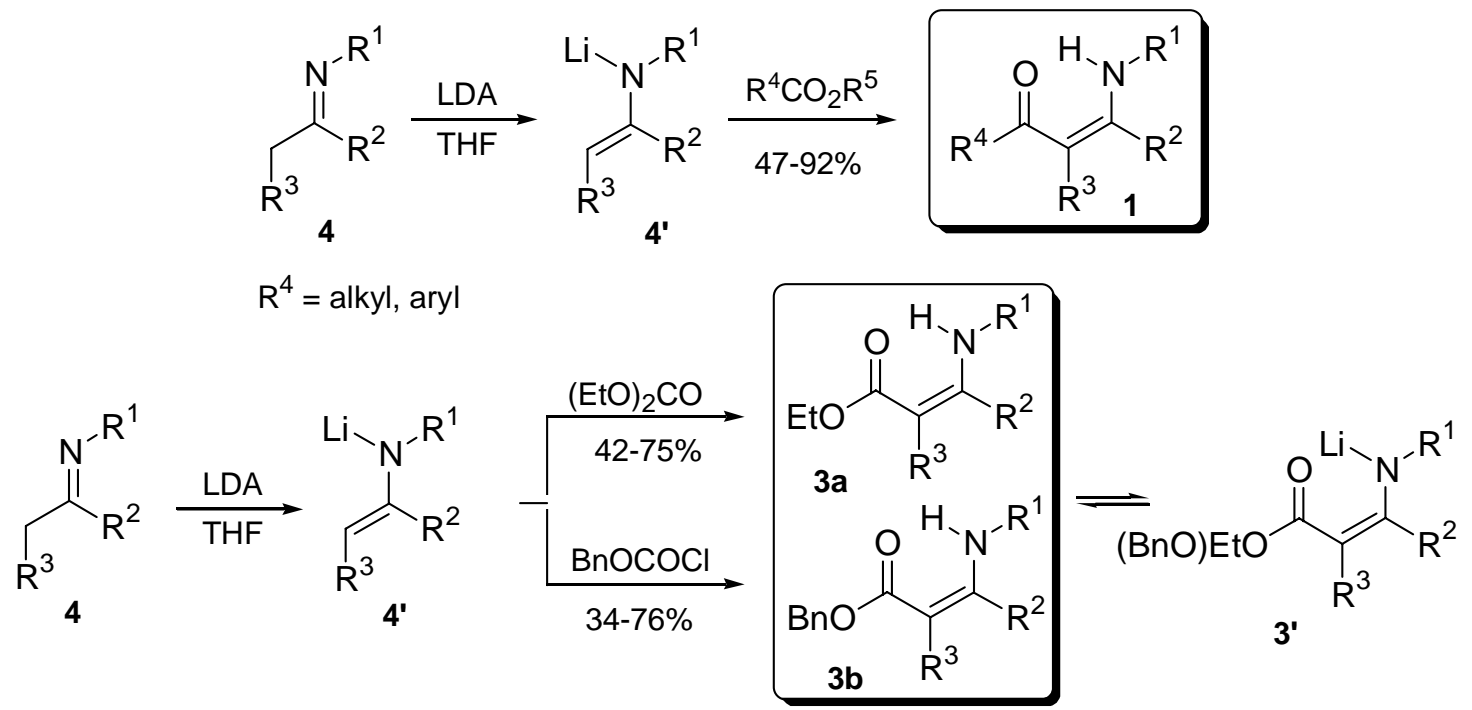

\section{Scheme 2}

\subsection{Other methods}

A new method for the regioselective preparation of $\beta$-enamino ketones 1 is the reaction of $\beta$ enamino esters 3 with organolithium reagents. ${ }^{20}$ This method circumvents the preparation of instable imines and through the opportune choice of $\beta$-enaminoester and organolithium reagents it allows the preparation of $\beta$-enaminoketones not available by condensation or imine acylation (Scheme 3).<smiles></smiles>

3

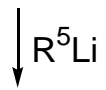

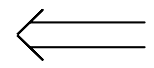

$(30-85 \%)$<smiles>[R]C(=[OH+])C([R])=C([R])N([Z])[K]</smiles>

1<smiles></smiles>

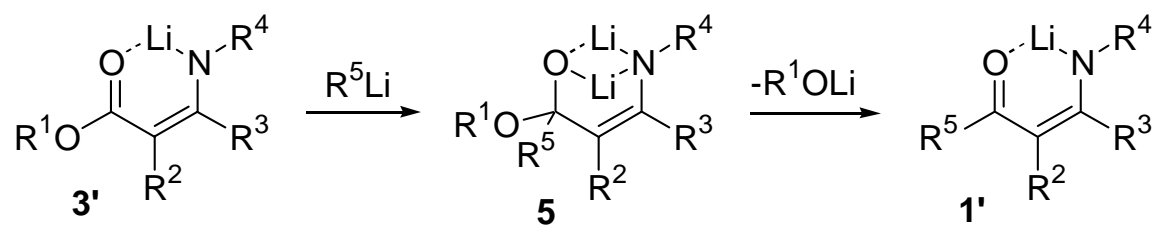

\section{Scheme 3}


Another method starts from isoxazoles or isoxazolium salts $\mathbf{6}$, that afford to various $\beta$ enamino ketones when submitted to reductive ring opening conditions with different reagents: EtMgBr/Ti(i-PrO) $4{ }_{4}{ }^{21}$ organocuprates $^{22}$ or with Raney nickel catalysis ${ }^{23}$ (Scheme 4).
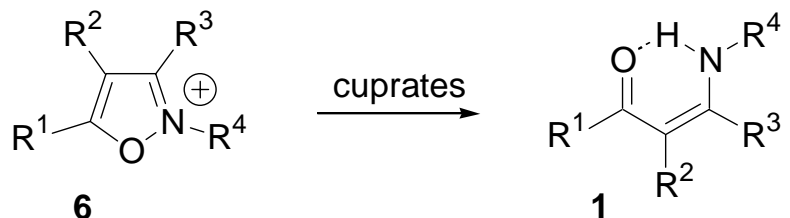

\section{Scheme 4}

An analogous approach on benzoxazoles allows the preparation of imidoyl phenols. ${ }^{2 \mathrm{~b}}$

In this last years fluorinated compounds have awaken a growing interest and also specific methods for the preparation of fluorinated $\beta$-enaminoketones have been developed. ${ }^{24}$

\section{Functionalization of enaminones}

\subsection{Regio- and stereoselective alkylation of enaminones}

The synthetic possibilities offered by $\beta$-enaminoketones can be increased by their functionalization (Scheme 5).
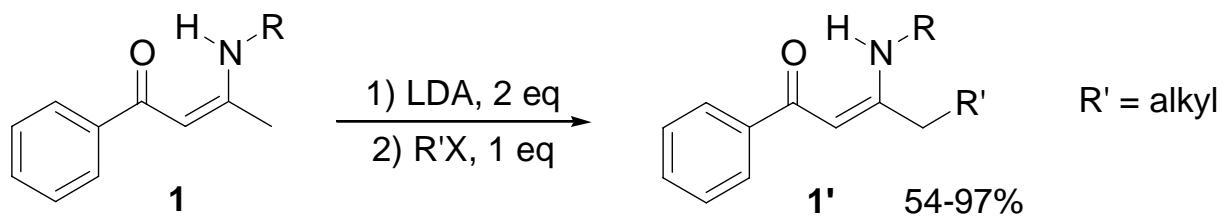

\section{Scheme 5}

In fact treatment of $\beta$-enaminoketones 1 with lithium amides affords to their dianions, that react with a wide serie of electrophiles affording to polyfunctionalized products. ${ }^{25}$

In suitable reaction condictions the deprotonation became regioselective, allowing the preparation of $\alpha$ ' or $\gamma$ - dianions of $\beta$-enaminoketones ${ }^{26}$ (Scheme 6): 


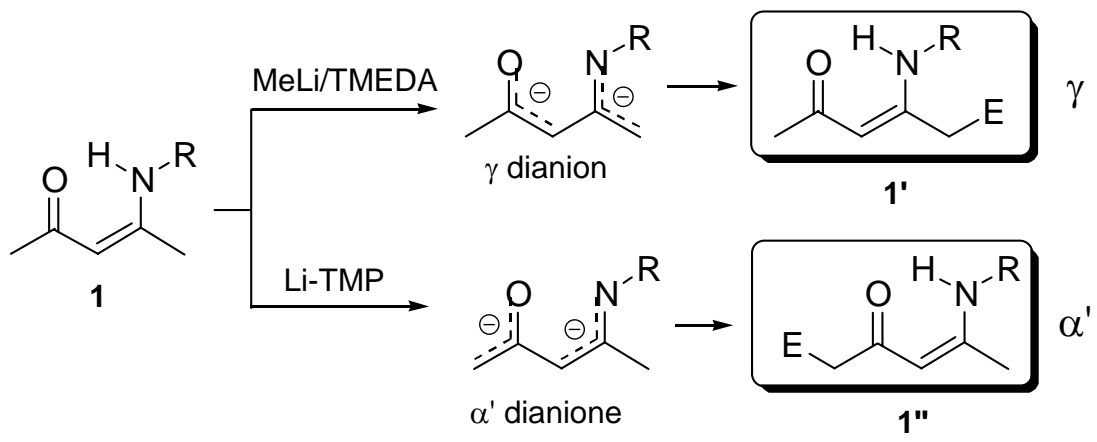

\section{Scheme 6}

The introduction of a chiral group bonded to nitrogen atom allows diastereoselective alkylation $^{28}$ (Scheme 7):<smiles>[M]C(NC1=C(C(=O)c2ccccc2)CCC1)c1ccccc1</smiles>

1

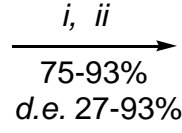

d.e. $27-93 \%$

i: 2.5 eq. MeLi/additive/THF, $40^{\circ} \mathrm{C}, 30^{\prime} ;$ ii: 1.5 eq. RI/THF, $-100{ }^{\circ} \mathrm{C}, 30^{\prime}$

\section{Scheme 7}

\subsection{Other functionalizations}

Enaminones can be regioselectively functionalized in many ways, through reaction with a wide range of electrophiles. These reactions open an access to several classes of compounds, sometimes unprecedented ${ }^{27}$ (Scheme 8). 


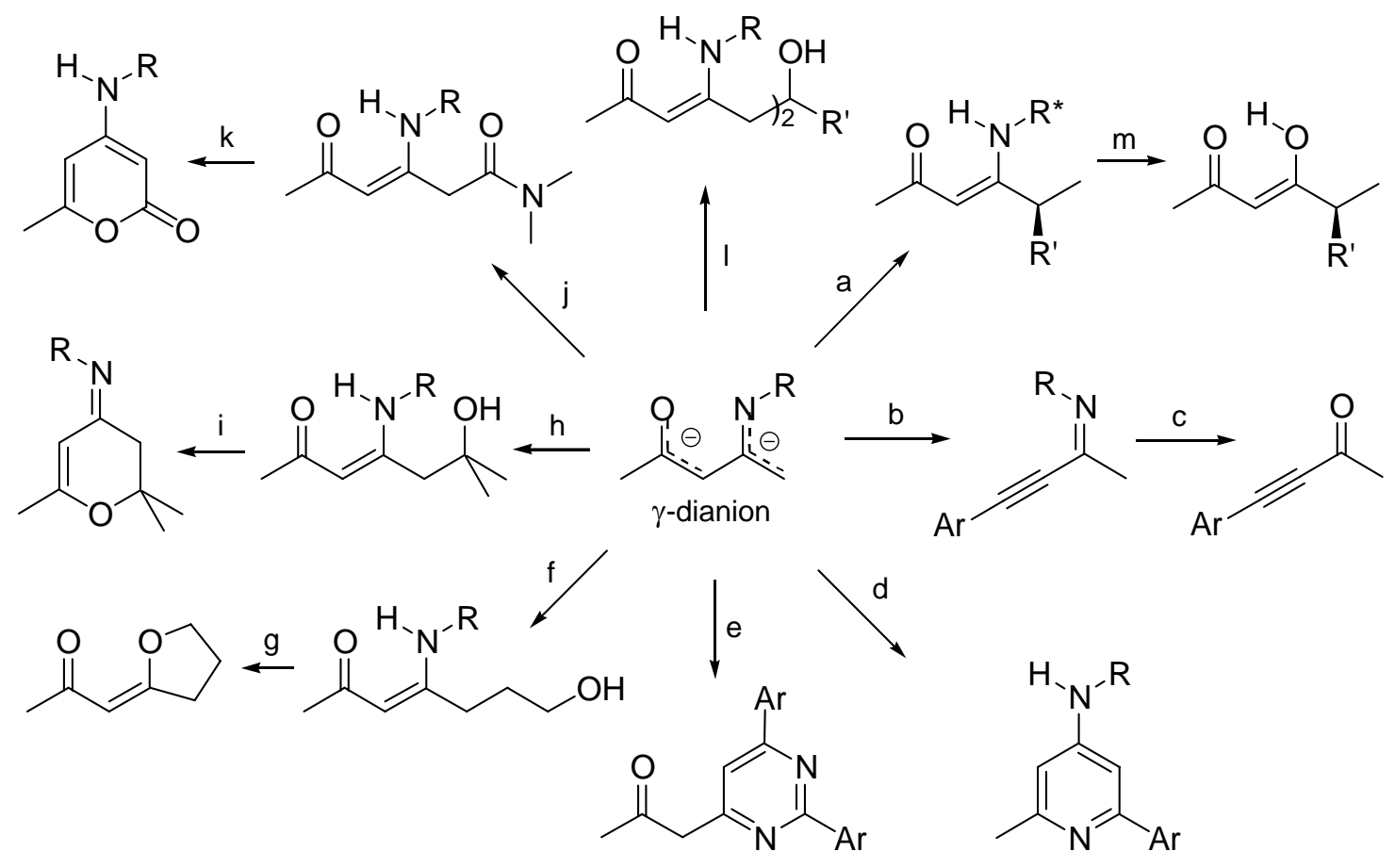

Reagents: a, R'X; b, $\mathrm{Me}_{3} \mathrm{SiCl} ; \mathrm{c}, \mathrm{AcOH}$; d, ArCN; f, ethylene oxide; g, $\mathrm{AcOH}$; $\mathrm{h}$, aldehyde or ketone; i, $\mathrm{HCl}$; j, $\mathrm{ClCONMe}_{2}$; $\mathrm{k}, \mathrm{HCl}$; I, ester; $\mathrm{m}, \mathrm{H}_{3} \mathrm{O}^{+}$.

\section{Scheme 8}

\section{Reductions}

\subsection{Introduction}

$\beta$-Amino esters $\mathbf{8}$ and $\gamma$-amino alcohols 7 are two classes of compounds very interesting for their intrinsic biological and pharmaceutical properties and for their wide applications in synthesis. ${ }^{29}$ The synthesis of $\gamma$-amino alcohols has been performed also from $\beta$-amino carbonyl compounds, as reviewed elsewhere. ${ }^{30}$ Owing to their structure, enaminones constitute very interesting starting materials for the preparation by reduction of these classes of compounds. The reduction of enaminones opens same interesting challenges about chemo- and diastereoselective reduction of $\beta$-enamino ketones and $\beta$-enamino esters (Scheme 9). 

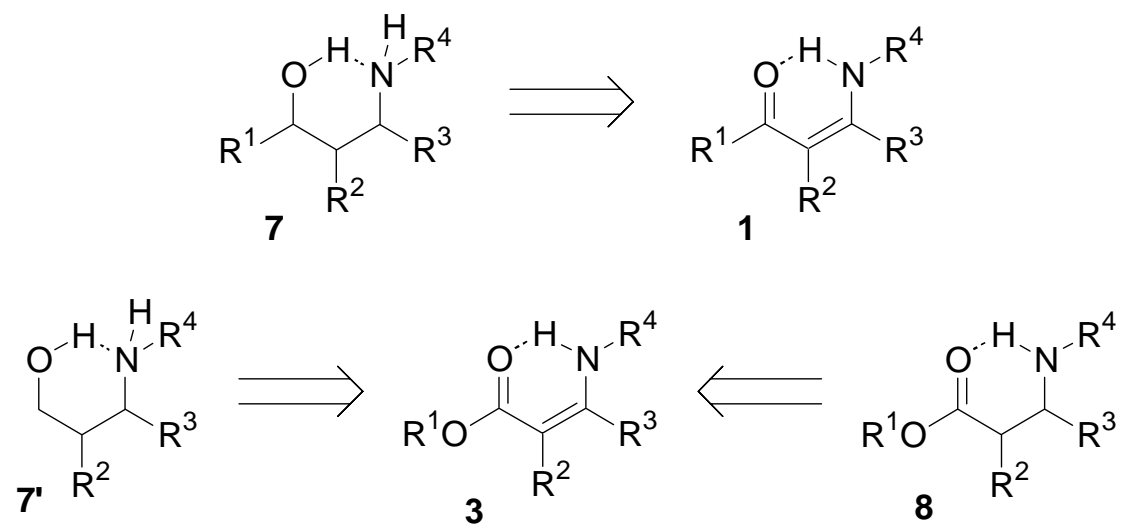

\section{Scheme 9}

Moreover $o$-hydroxybenzylamines 9 constitute an important class of useful pre-catalysts for the addition of dietilzinc to aldehydes, ${ }^{31}$ and find an ideal precursor in imidoyl phenols 2 (Scheme 10).
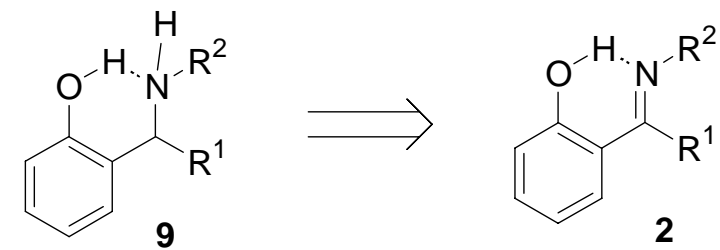

\section{Scheme 10}

\subsection{Chemo- and stereoselective reductions}

4.2.1 Reduction of $\boldsymbol{\beta}$-enamino ketones to $\boldsymbol{\gamma}$-amino alcohols Dissolving metals reduction of enaminones was explored with sodium and isopropanol and resulted in the complete reduction of the unsatured system. ${ }^{32} \beta$-Enamino ketones $\mathbf{1}$ affords to secondary $\gamma$-aminoalcohols 7 in syn configuration predominantly, while $\beta$-enamino esters afforded to the corresponding primary $\gamma$ aminoalcohols 7', (Scheme 11). 

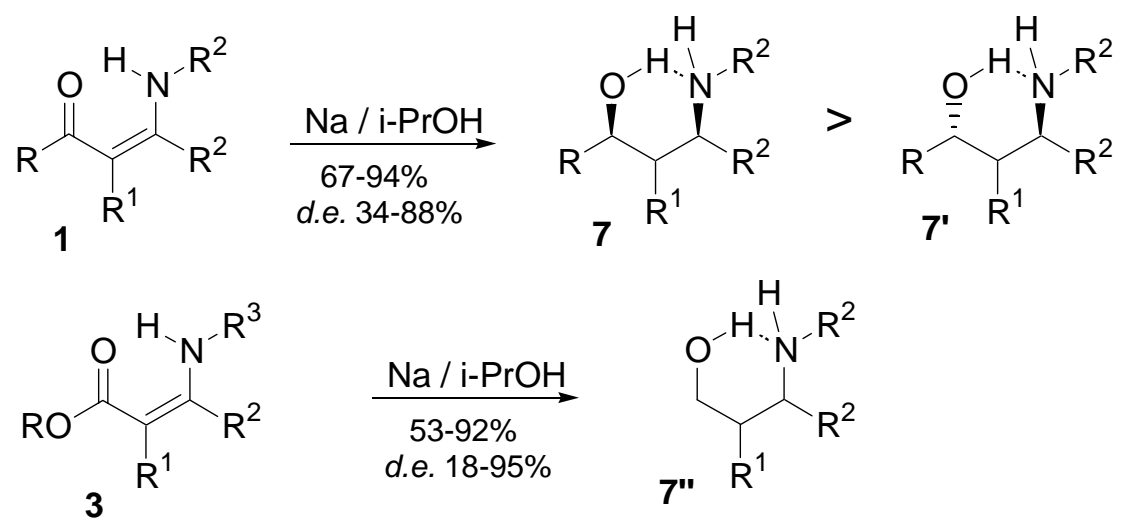

\section{Scheme 11}

Reduction of $\beta$-enamino ketones to syn $\gamma$-amino alcohols 7 was performed also with $\mathrm{CeCl}_{3} / \mathrm{LiBH}_{4}$ system in moderate to good yields and $d e^{33}$ (Scheme 12).

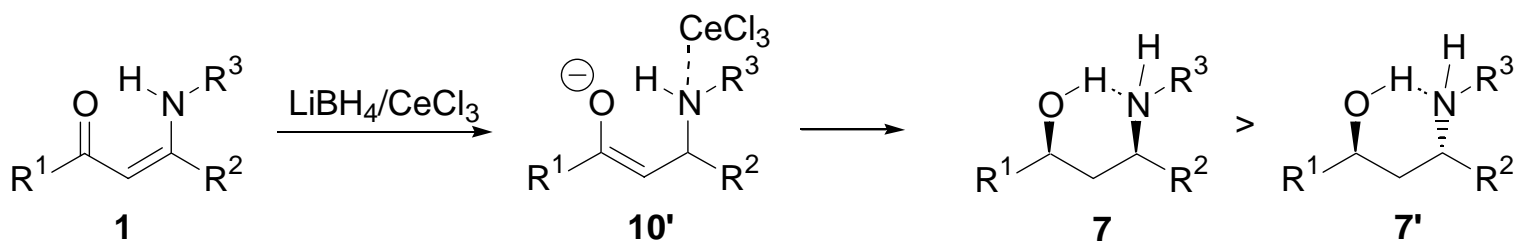

\section{Scheme 12}

Secondary $\beta$-enamino ketones were reduced in acid solution of trifluoroacetic acid in isopropanol as solvent, with $\mathrm{NaBH}_{4}{ }^{34}$ After workup, $\alpha, \beta$-unsatured ketones 11 were obtained in 60$80 \%$ yield, in trans olefinic structure (Scheme 13):

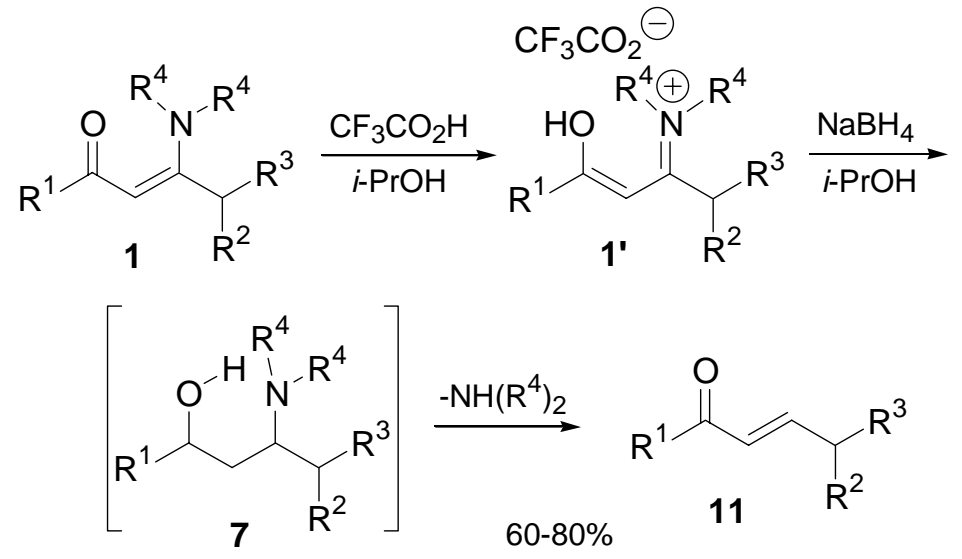

\section{Scheme 13}


The chemoselective reduction of $\beta$-enamino ketones ${ }^{35}$ has been performed also with different reducing systems, as $\mathrm{LiAlH}_{4}-\mathrm{Cu}, \mathrm{PtO}_{2}, \mathrm{LAH}$, for the preparation of $\beta$-amino ketones $\mathbf{1 0}$ (yield = $35-70 \%$, Scheme 14). Side reactions were observed, as deamination with enone production, expecially with $\mathrm{LiAlH}_{4}$, with or without $\mathrm{Cu}$.

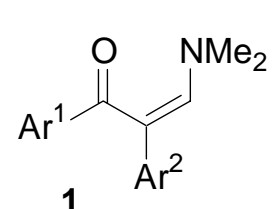

1

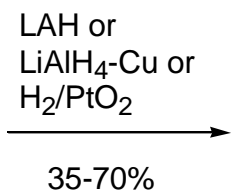

$35-70 \%$<smiles>CN(C)CC(Br)C(=O)[Al]</smiles>

10

$(35-70 \%)$

\section{Scheme 14}

The reduction of $\beta$-enamino ketones $\mathbf{1}$ also is possible with sodium triacetoxy borohydride and was performed in glacial acetic acid. ${ }^{40} \gamma$-Amino alcohols are obtained in $70-98 \%$ yields in syn configuration predominantly (de 44-99\%) as ascertained by analysis of the corresponding tetrahydro oxazine derivatives. The same authors have also patented this procedure. ${ }^{41}$

The same reaction has been performed on chiral starting materials. The hypotized mechanism is reported in Scheme 15: ${ }^{42}$

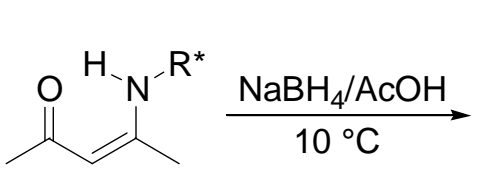

1

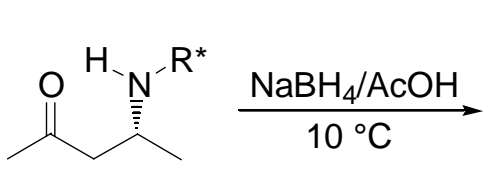

10

$\mathrm{R}^{*}-\mathrm{NH}_{2}=(R)$-1-phenylethylamine

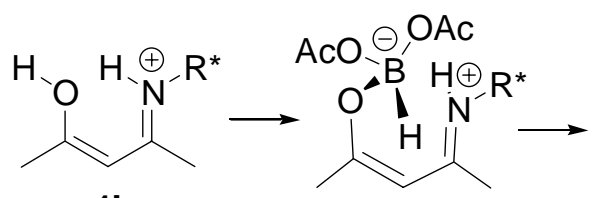

$1^{\prime}$

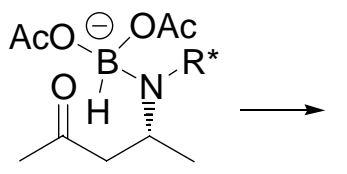

C

isolated yield of the major diastereomer $48-62 \%$.

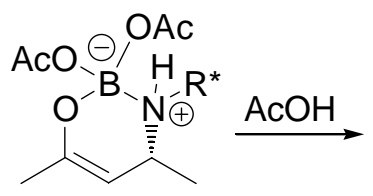

B

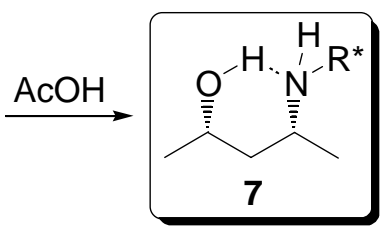

$\mathrm{AcO} \ominus \mathrm{OAC}$

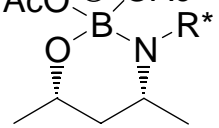

D

\section{Scheme 15}

The reduction takes place in two steps: first the reduction of the iminium ion in the protonated starting $\beta$-enamino ketone (1'), through hydride transfer from the intermediate boro enolate $\mathbf{A}$, then the subsequent reduction of the carbonyl group by the aminodiacetoxyborohydride complex $\mathbf{C}$. The reduction of the iminium ion affords to two diastereomers intermediate $\beta$-amino ketones 8. On this intermediate $\mathbf{A}$ the hydride transfer can take place either on $R e$ or on $S i$ face respectively. The corresponding transition states for the two situations differ of $1.21 \mathrm{Kcal} / \mathrm{mol}$, being the $R e$ the less stable because of to the steric hindrance between phenyl group and the diacetoxyborohydride group (Figure 4). 


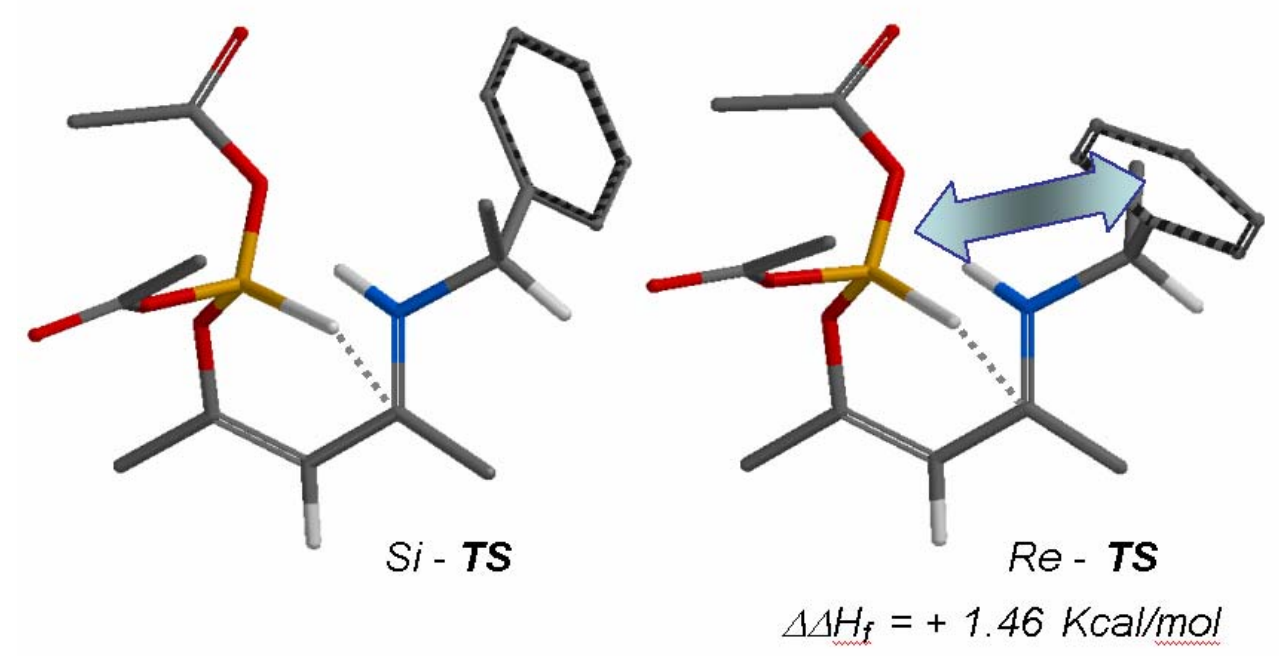

Figure 4. More stable optimized structures for the $S i$ and $R e$ Transition States in the first step of the stereoselective reduction of $\beta$-enamino ketones 1 to $\beta$-amino ketones $\mathbf{1 0}$.

The syn stereochemistry of the second reaction step is easily explained examining the two transition states $\mathbf{C}$ for the hydride transfer in the reduction of the carbonyl group (Scheme 15).

Oxazines 13 and oxazinones 14 can be easily prepared by cyclization of enantiopure $\gamma$-amino alcohols 7 with formaldehyde or carbonyl diimidazole respectively (Scheme 16).

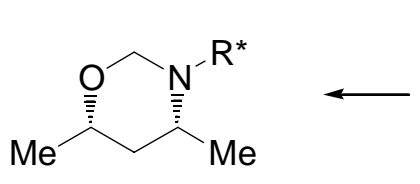

13

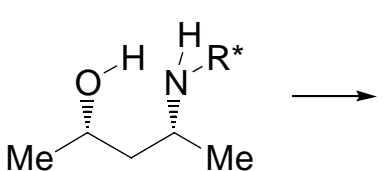

7<smiles>[R7]N1C(=O)O[C@H](C)C[C@@H]1C</smiles>

14

$\mathrm{R}^{*}-\mathrm{NH}_{2}=(R)$-1-phenylethylamine

\section{Scheme 16}

The formation of oxazines $\mathbf{1 3}$ takes place with retention of the absolute configuration of the stereogenic centres present in the $\gamma$-amino alcohols 7 , while in the reaction with carbonyl diimidazole, in the presence of diethylamino pyridine, inversion of configuration at C-6 was observed. Epimerization of cis oxazinones $\left(4 R, 6 S, 1^{\prime} R\right)-\mathbf{1 4}$, initially formed, takes place through the open molecule $(R, R)-\mathbf{1 5}$, affording to the thermodynamically more stable trans oxazinones $(R, R, R)-14$ (Scheme 17). 


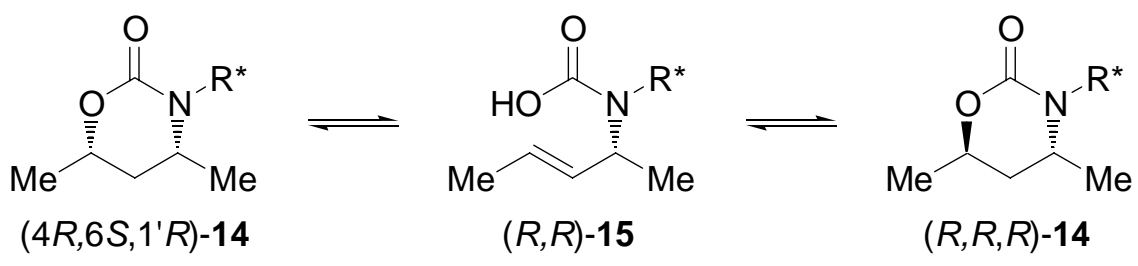

$\mathrm{R}^{*}-\mathrm{NH}_{2}=(R)$-1-phenylethylamine

\section{Scheme 17}

$\gamma$-Aminoalcohols present a strong $\mathrm{H}$-bond between the hydroxy proton and the nitrogen atom, as found in the more stable conformation obtained from conformational analysis by molecular modeling and as confirmed by X-ray structure determination (Figure 5).

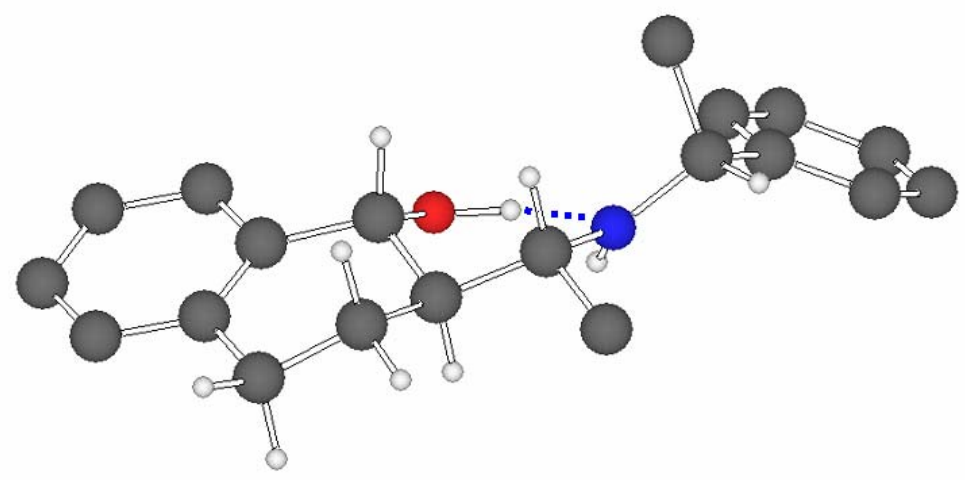

Figure 5. X-ray structure of the $\gamma$-amino alcohols showing the tipical cyclic conformation stabilized by the strong intramolecular H-bond.

4.2.2 Reduction of $\boldsymbol{\beta}$-enamino esters to $\boldsymbol{\beta}$-amino esters and $\boldsymbol{\beta}$-amino acids The interest in $\boldsymbol{\beta}$ amino esters $\mathbf{8}$ has stimulated the search for chemoselective reduction of the carbon-carbon double bond of $\beta$-enamino esters in the presence of the carbonyl function. ${ }^{5}$

The reaction of $\beta$-enamino esters with sodium triacethoxy borohydride is a convenient and economic way for this reduction ${ }^{36}$ (Scheme 18).
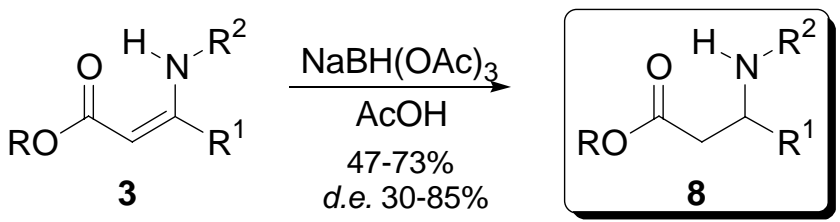

\section{Scheme 18}


The same reaction has been applied to a diastereoselective entry to $\beta$-amino esters $\mathbf{8}$ starting from $\beta$-enamino esters either cyclic ${ }^{37}$ (Scheme 19) or chiral $^{38}$ (Scheme 20).
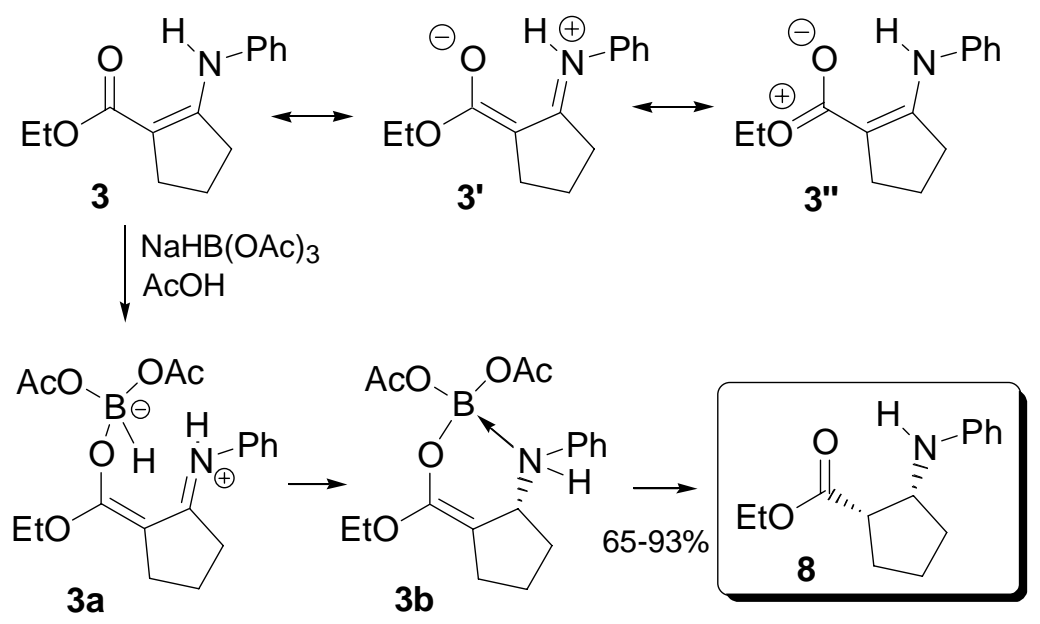

\section{Scheme 19}<smiles>[R]OC(=[OH+])/C([R])=C(/[R])N([CH])c1ccccc1</smiles>
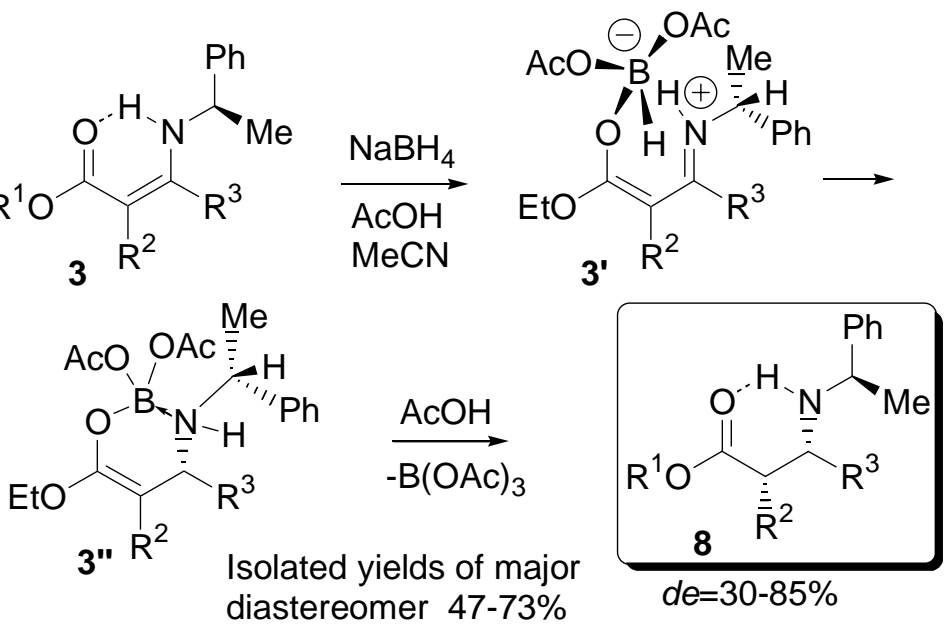

\section{Scheme 20}

In this case the diastereoselectivity is explained on the basis of the structure of the hypotized enol ester-diacethoxy boridride intermediate, in which the hydride ion is transferred on the less hindered si face of the iminium ion double bond, as depicted in Figure 6. 


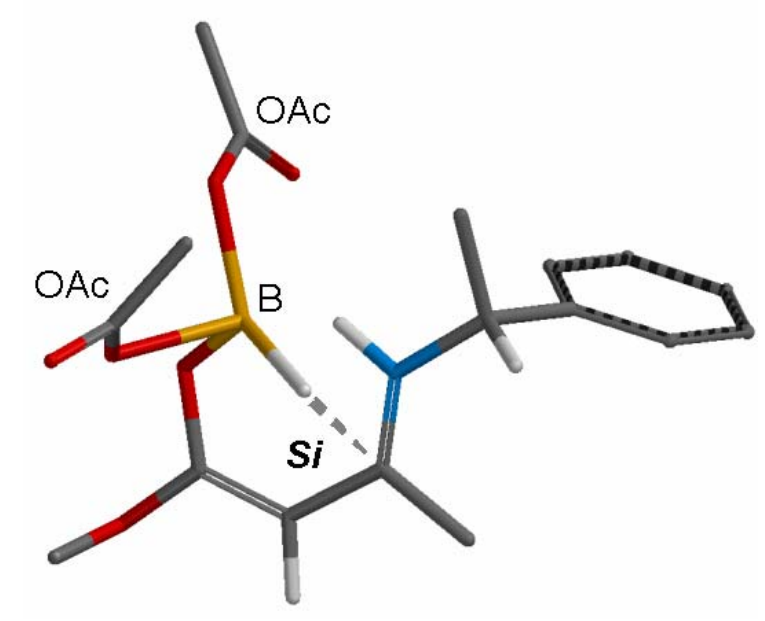

Figure 6. More stable optimized structure for the Transition State in the stereoselective reduction of $\beta$-enamino esters $\mathbf{3}$ to $\beta$-amino esters 8 .

A combined application of reductive methodologies allows the preparation of both diastereomers of a $\gamma$-amino alcohol, starting from the same precursor $\mathbf{3}^{36}$ (Scheme 21).

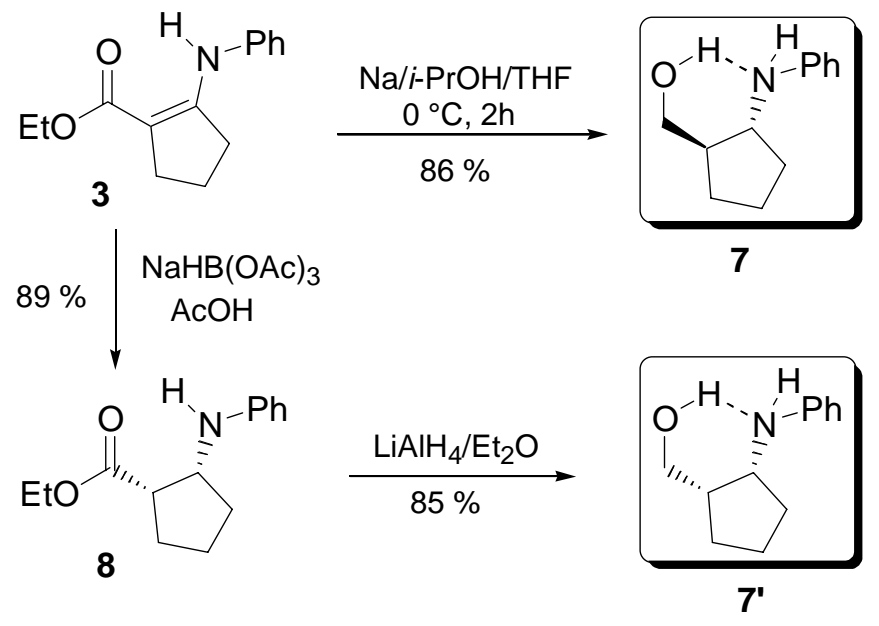

\section{Scheme 21}

These methodologies have allowed the development of a simple and straightforward procedure for the synthesis of homochiral $\beta$-aminoacids, ${ }^{39}$ through use of the easily hydrogenolizable chiral $(R)$-phenylethylamine as chiral source. Particularly has been prepared the enantiopure $\beta$-aminoacid cispentacine (12) active against Candida Albicans (Scheme 22). 


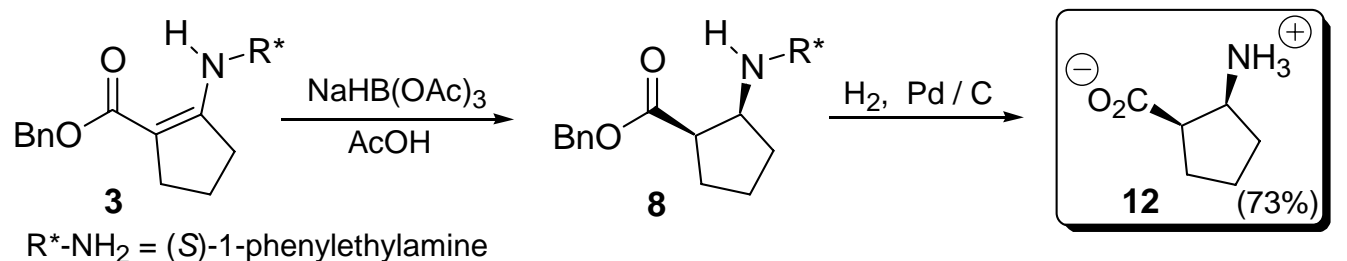

\section{Scheme 22}

4.2.3 Reduction of imidoyl phenols to o-hydroxybenzylamines $o$-Hydroxybenzylamines 9 are an important class of useful pre-catalysts used in the enantioselective addition of dietilzinc to aldehydes. ${ }^{6 a}$ Imidoyl phenols 2 constitute a good precursor for the preparation of these molecules by reduction (Scheme 10) with $\mathrm{NaBH}_{4} / \mathrm{AcOH}, \mathrm{NaBH}_{4} / \mathrm{CeCl}_{3} / \mathrm{MeOH}^{6 \mathrm{a}}$ and $\mathrm{Zn}\left(\mathrm{BH}_{4}\right)_{2} / \mathrm{THF}$. ${ }^{6}$

Treatment of imidoyl phenols with zinc borohydride in THF allows the stereoselctive synthesis of homochiral $o$-hydroxybenzylamines (Scheme 23). The stereochemical outcome of this reaction is easily explained on the basis of the model of the transition state for the hydride transfer, that take place on the less hindered si face of the imine double bond. Owing to the presence of the coordinating oxygen atom, imidoyl phenols show a very major diastereoselectivity with respect to the corresponding imines. In Figure 7 are reported the two different hypotized transition states that differ of $1.46 \mathrm{Kcal} / \mathrm{mol}$, being the transfer of the hydride on the $s i$ face more favoured.<smiles>[R]C(=N[C@@H](C)c1ccccc1)c1ccccc1O</smiles>

yield of the pure isolated stereoisomer $54-69 \%$ d.e. $56-83 \%$

\section{Scheme 23}




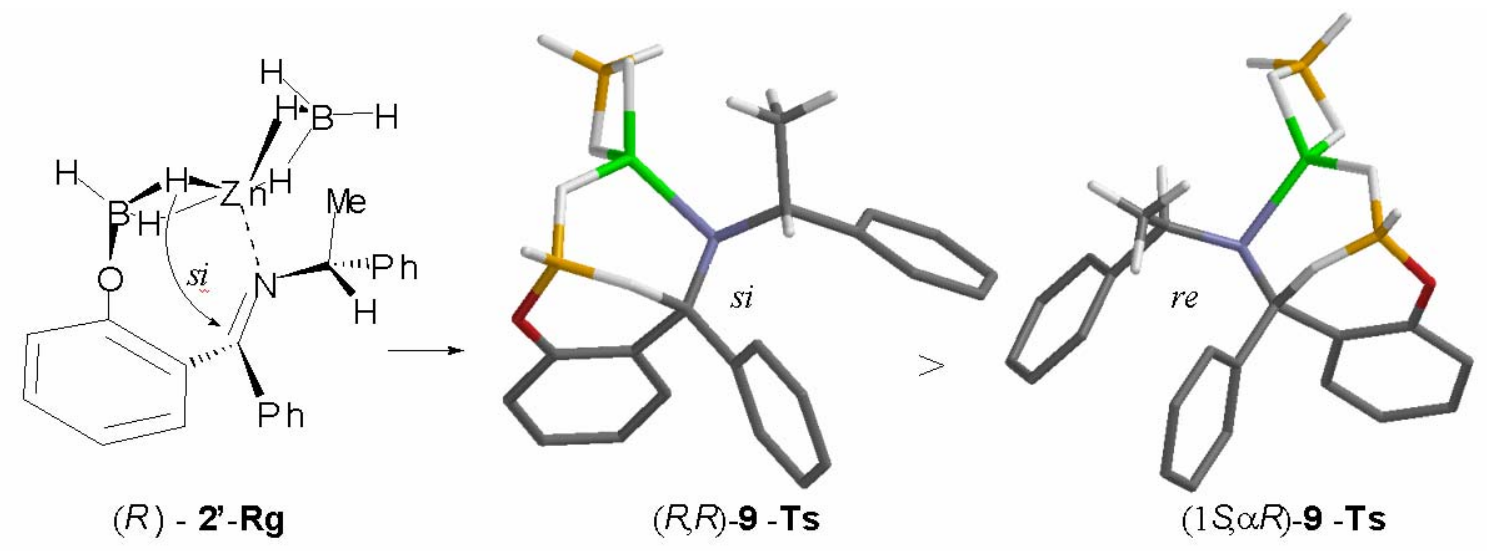

Figure 7. Transition states $(R, R)-9-$ Ts and $(1 S, \alpha R)-9-T s$, minimized at the PM3 semiempirical level, for the intramolecular hydride transfer on the si or re face of the imine $(R)-2$ '-Rg.

\subsection{Addition reduction one-pot procedures}

Another synthetic route to $\gamma$-aminoalcohols has been developed by addition of organolithium reagents on enaminones, followed by one pot reduction with sodium triacethoxy borohydride in methanol. Both $\beta$-enamino ketones and $\beta$-enamino esters can be submitted to this methodology, affording to $\gamma$-aminoalcohols with good results.

$\beta$-Enamino esters 3 react with organolithium reagents ${ }^{43}$ in toluene affording to an intermediate $\beta$-imino alcohol 16. The reaction mixture is then quenched with methanol and added of acetic acid and sodium borohydride. In these conditions the reduction to $\gamma$-amino alcohol 7 of the intermediate takes place (Scheme 24).

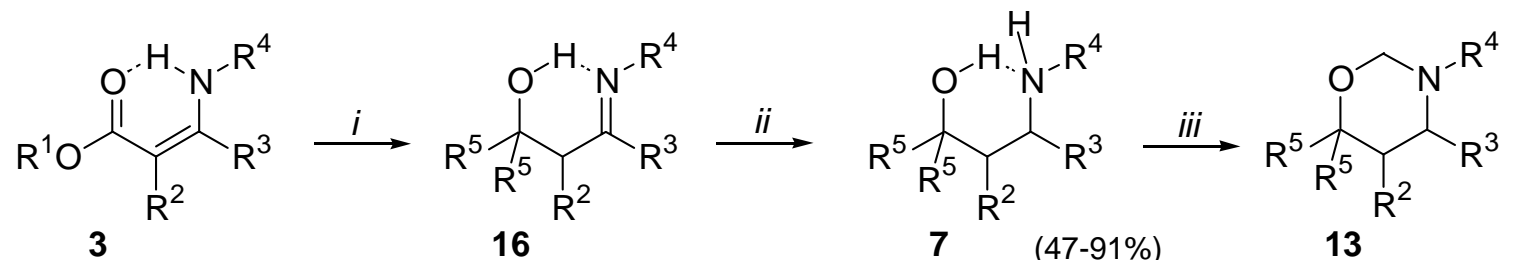

(i) $\mathrm{R}^{5} \mathrm{Li}, 4.0$ eq., toluene. (ii) $\mathrm{NaBH}(\mathrm{OAc})_{3}, \mathrm{MeOH}, 1 \mathrm{~h}, 0^{\circ}$. (iii) $\mathrm{CH}_{2} \mathrm{O}, \mathrm{THF} / \mathrm{H}_{2} \mathrm{O}, 6$, r.t..

\section{Scheme 24}

In the mechanism proposed for this reaction, the first organolithium molecule acts as base extracting the aminic proton $\left(\mathbf{1}^{\prime}\right)$. Then a second molecule of organolithium compound attacks the carbonyl function and the substitution of the alkoxy group takes places. Then a third molecule of organolithium reagent attack the carbonyl group of the intermediate $\beta$-enamino ketone affording to the intermediate $\beta$-imino tertiary alcohol. The addition of sodium 
borohydride in the acid methanolic reaction mixture affords to a boron alkoxy intermediate on which takes place the hydride transfer and the reduction of the imine group (7).

The addition of only one molecule of organolithium compound on the starting $\beta$-enamino ester affords to an intermediate $\beta$-enamino ketone 1, that can be isolated, as showed in scheme 24. Alternatively, it is possible the addition of two different organolithium reagents, one by another, and the isolation of the corresponding tertiary $\gamma$-aminoalcohol with two different alkyl groups geminal to the hydroxy function (Scheme 25).

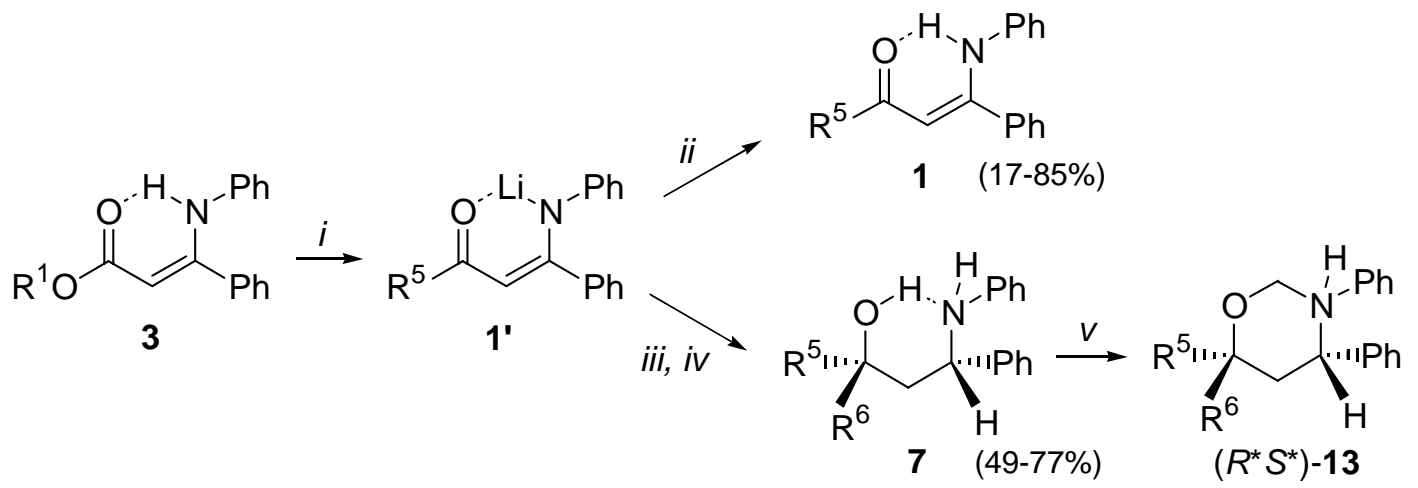

(i) $\mathrm{R}^{5} \mathrm{Li}$, (ii) $\mathrm{H}_{3} \mathrm{O}^{+}$, (iii) $\mathrm{R}^{6} \mathrm{Li}$, (iv) $\mathrm{NaBH}(\mathrm{OAc})_{3}, \mathrm{MeOH}$, (v) $\mathrm{CH}_{2} \mathrm{O}$

\section{Scheme 25}

Analogously, it is possible to perform this methodology directly on $\beta$-enamino ketones ${ }^{52}$ (Scheme 26):<smiles>[R4]C1=CN(C2=C([R])C=C([R1])CN2)[OH+][CH]1</smiles>

1<smiles>[R]C(CC([R])([R])O[13CH3])Nc1ccccc1</smiles><smiles>[R]C(=[OH+])C([R])=CC([R])=[Cr]</smiles>

$1 '$

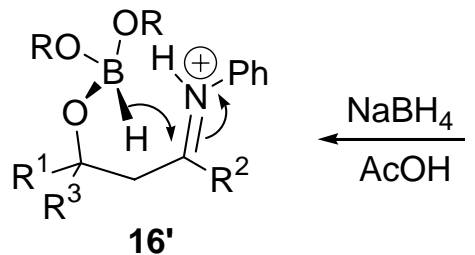

$\stackrel{\mathrm{R}^{3} \mathrm{Li}}{\longrightarrow}$

$16^{\prime}$<smiles>[R]C1=CC([R])([R])O[Al]N1[Al]([AlH2])c1ccccc1</smiles>

16

$\mathrm{MeOH}$

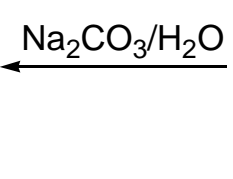<smiles>[R]C(CC([R])([R])O)=NPc1ccccc1</smiles>

\section{Scheme 26}




\section{Applications of $\beta$-enamino esters reduction to the synthesis of biologically active compounds}

Diastereoselective chemical reduction of $\beta$-enamino esters is the critical stereochemical step in several syntheses of piperidine alkaloids, ${ }^{45}$ for example, in the formal enantioselective synthesis of $(+)$-calvine ${ }^{46}$ (Scheme 27).

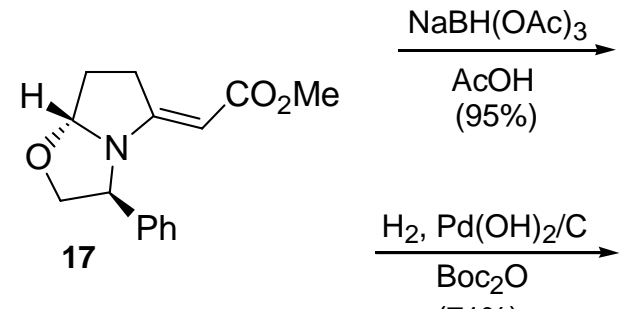

$(71 \%)$
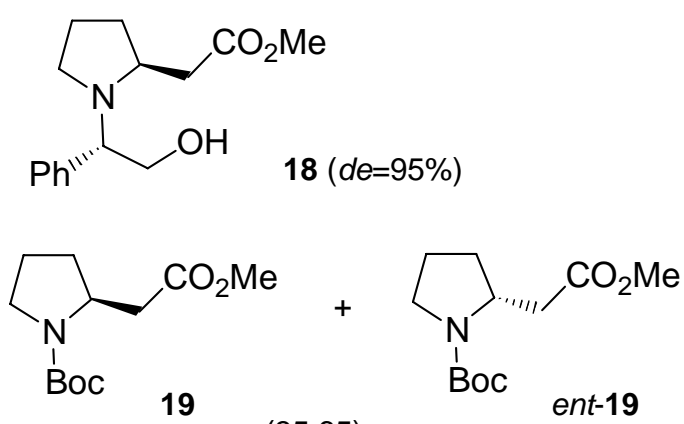

$(35: 65)$

\section{Scheme 27}

Catalytic hydrogenation has also been applied to the diastereoselective synthesis of cis-2,6disubstituted piperidine alkaloids. ${ }^{47}$ Both, catalytic hydrogenation and chemical reduction with sodium triacetoxy borohydride, were applied to the enantioselctive synthesis of $(+)$-tashiromine, $(+)$-laburnine and (-)-isoretronecanol ${ }^{48}$ and take part in the preparation of (-)-indolizidine 239 $\mathrm{AB}$, that, like other 3,5-disubstituted indolizidines, constitutes an important bicyclic skeleton of several alkaloids with neuromuscolar activity, coming from Dendrobatidae poison frogs ${ }^{49}$ (Scheme 28) or ant venoms in the related genera Monomorium and Solenopsis, many of which display significant biological activity. ${ }^{50}$<smiles>O=C1CC[C@@H](C(=O)O)N1</smiles>

20

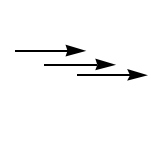

OH

21
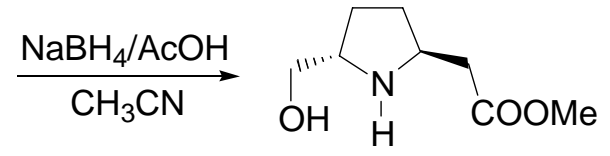

22

\section{Scheme 28}

These reactions constitute stereoselective key step also in the preparation of carbapenem and penem antibiotics. $^{51}$

Reductive procedures are also used in the preparation of 2-azetidinones $\mathbf{2 6}$ from $\beta$-enamino keto esters 23, ${ }^{51}$ as depicted in Scheme 29. 


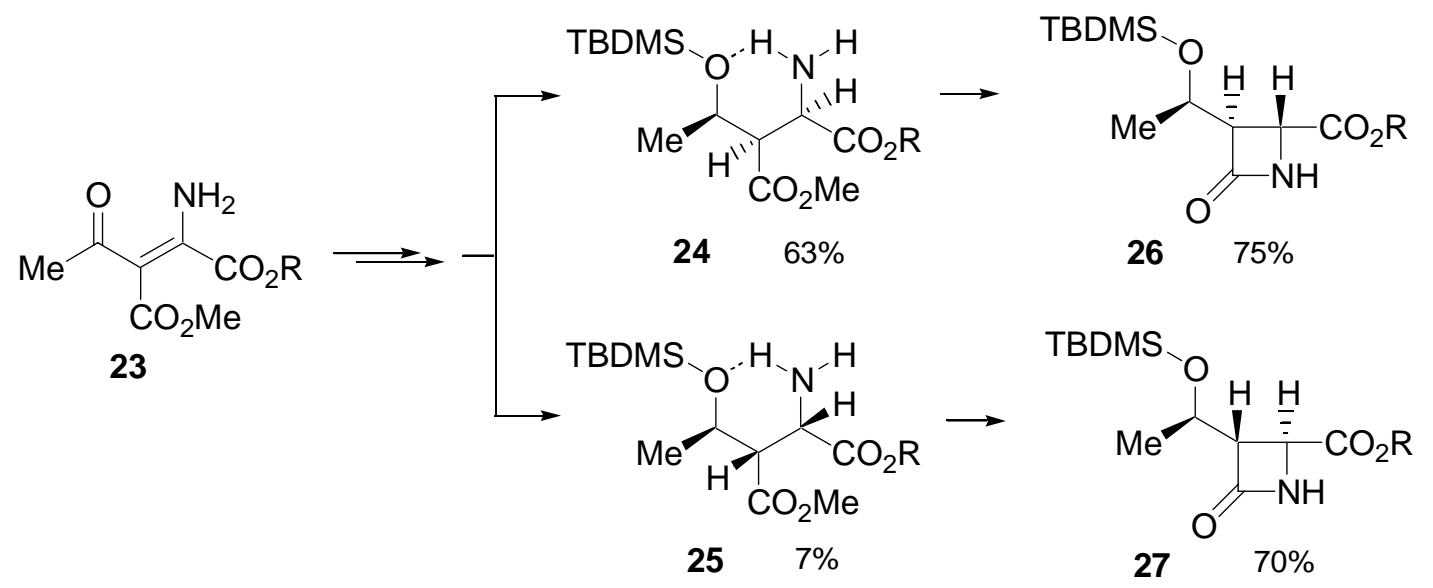

Scheme 29

\section{Conclusions}

In summary, in this paper the chemistry of the preparation of $\beta$-enamino ketones and $\beta$-enamino esters is described and their use as useful starting materials in reductive procedures for the preparation of biologically active natural products. Compounds containing the enaminone system are very stable and have a long shelf life, also in room conditions. At the same, time they can be easy prepared starting from cheap and easily available reagents; therefore, they can be considered excellent starting materials for organic synthesis. Several chemo- and regioselective methodologies for their preparation were developed, also recently. The possibility of the use of chiral enantiopure amines in the preparation of $\beta$-enamino esters and $\beta$-enamino ketones makes available starting materials very useful for the synthesis of several enantiopure compounds. Moreover, it is possible to prepare more complex enaminones by regio- and stereoselective functionalization of the more easily accessible one.

Starting fom $\beta$-enamino ketones and $\beta$-enamino esters, it is possible to prepare biologically active compounds by simple reduction or alkylation followed by reduction. The regio- and stereoselective methodologies developed result useful alternative pathways to the numerous literature procedures for the preparation of $\gamma$-amino alcohols, $\beta$-amino acids, aminoalkyl phenols and their derivatives. Reduction products, as $\gamma$-aminoalcohols, aminoalkyl phenols and their derivatives, are very stable compounds that find useful applications in asymmetric catalysis as chelant for the preparation of chiral enantiopure metallic catalysts.

\section{Acknowledgements}

Financial support of this research by grant from University of Camerino and from MIUR-PRIN (contract no. 2005037725_001) is gratefully acknowledged. 


\section{References and Notes}

1. Greenhill J. V. Chem. Soc. Rev. 1977, 6, 277-294.

2. (a) Elassar A. A., El-Khair A. A. Tetrahedron 2003, 59, 8463. (b) Negri, G.; Kascheres, C.; Kascheres, A. J. J. Heterocyclic Chem. 2004, 41, 461.

3. Cimarelli, C.; Palmieri, G.; Recent Res. Devel. In Organic Chem. 1 1977, 179.

4. (a) Bartoli, G.; Cimarelli, C.; Marcantoni, E.; Palmieri, G.; Petrini, M. J. Org. Chem. 1994, 59 , 5328. (b) Bartoli, G.; Cimarelli, C.; Palmieri, G. J. Chem.Soc., Perkin Trans. 1 1994, 537.

5. (a) Juaristi, E.; Enantioselective synthesis of $\beta$-amino acids, Wiley-VCH, New York, 1997.

(b) Juaristi, E.; Quintana, D.; Escalante, J. Aldrichim. Acta 1994, 27, 3. (c) Davies, S. G.; Walters, I. A.; S. J. Chem. Soc. Perkin Trans 1 1994, 1129. (d) Enders, D.; Wahl, H.; Bettray, W.; Angew. Chem., Int. Ed. 1995, 34, 455. (e) Cole, D. C.; Tetrahedron 1994, 50, 9517. (f) Georg, G. I., Ed. The Organic Chemistry of $\beta$-Lactams, VCH: New York, 1993. (g) Cardillo, G.; Tomasini, C. Chem. Soc. Rev. 1996, 25, 117.

6. (a) Palmieri, G. Eur. J. Org. Chem. 1999, 65, 805. (b) Cimarelli, C.; Palmieri, G.; Tetrahedron: Asymm. 2000, 2555.

7. (a) Brown, N. M. D.; Nonhebel, D. C. Tetrahedron 1968, 24, 5655; (b) Sharma, R. K., Singh, R. V. Tandon, J. P. J. Inorg. Nuclear Chem. 1980, 42, 1382.

8. Braibante, H. T. S.; Braibante, M. E. F.; Rosso, G. B.; Oriques, D. A. J. Braz. Chem. Soc. 2003, 14, 994.

9. Valduga, C. J.; Squizani, A.; Braibante, H. S.; Braibante, M. E. F. Synthesis 1998, 1019.

10. Zhao, Y.; Zhao, J.; Zhou, Y.; Lei, Z.; Li, L.; Zhang, H., New J. Chem. 2005, 29, 769.

11. Bartoli, G.; Bosco, M.; Locatelli, M.; Marcantoni, E.; Melchiorre, P.; Sambri, L. Synlett 2004, (2), 239.

12. Khodaei, M. M.; Khosropour, A. R.; Kookhazadeh, M. Can. J. Chem. 2005, 83, 209.

13. Khosropour, A. R.; Khodaei, M. M.; Kookhazadeh, M. Tetrahedron Lett. 2004, 45, 1725.

14. Labelle, M., Gravel. D. J. Chem. Soc. Chem. Commun. 1985, 105.

15. Bartoli, G.; Cimarelli, C.; Dalpozzo, R.; Palmieri, G.; Tetrahedron 1995, 51, 8613.

16. Abdulla, R. F.; Brinkmeyer, R. S. Tetrahedron 1979, 35, 1675.

17. (a) Stanovnik, B.; Svete, J. Chem. Rev. 2004, 104, 2433. (b) Stanovnik, B.; Svete, J. Synlett 2000, 1077. (c) Stanovnik, B.; Svete, J. Targets in Heterocyclic Systems 2000, 4, 105. (d) Cebasek P.; Wagger J.; Bevk D.; Jakse R.; Svete J.; Stanovnik B. J. Comb. Chem. 2004, 6, 356.

18. Cimarelli, C.; Palmieri, G.; Volpini, E.; Org. Prep. Proced. Int. 2001, 33, 369.

19. Bartoli, G.; Cimarelli, C.; Palmieri, G.; Bosco, M.; R. Dalpozzo Synthesis, 1990, 895.

20. Cimarelli, C.; Palmieri, G.; Volpini, E.. Tetrahedron Lett. 2004, 45, 6629.

21. Churykau, D. H.; Zinovich, V. G.; Kulinkovich, O. G. Synlett 2004, 1949. 
22. (a) De la Cal, M. T.; Cristobal, B. I.; Cuadrado, P.; Gonzalez, A. M.; Pulido, F. J. Synth. Commun. 1989, 19, 1039. (b) Alberola, A.; Gonzalez, A. M.; Laguna, M. A.; Pulido, F. J. Synth. Commun. 1986, 16, 673.

23. Kenar, J. A. J. Am. Oil Chem. Soc. 2003, 80, 1027.

24. (a) Wu, Y.-M.; Li, Y.; Deng, J. Tetrahedron Lett. 2005, 46, 5357. (b) Zouaoui, E.; Rezgui, F.; El Gaied, M. M. J. Chem. Res. 2004, 811. (c) Jeong, I. H.; Jeon, S. L.; Kim, M. S.; Kim, B. T. J. Fluor. Chem. 2004, 125, 1629. (d) Jeong, I. H.; Jeon, S. L.; Kim, M. S.; Kim, B. T. Tetrahedron Lett. 2002,.43, 7171. (e) Barten, J. A.; Kadyrov, A. A.; Lork, E.; Roschenthaler, G.-V. J. Fluor. Chem. 2002, 116, 87. (f) Kacharova, L. M.; Kacharov, A. D.; Gerus, I. I. J. Fluor. Chem. 2001, 111, 29. (g) Przyborowski, J.; Lork, E.; Roschenthaler, G.V. J.Fluor. Chem. 2000, 104, 207. (h) S. Fustero, M. G. de la Torre, B. Pina, A. S. Fuentes. J. Org. Chem. 1999, 64, 5551. (i) Gerus, I. I.; Gorbunova, M. G.; Kukhar, V. P. J. Fluor. Chem. 1994, 69, 195.

25. Bartoli, G.; Bosco, M.; Cimarelli, C.; Dalpozzo, R.; Palmieri, G. Synlett 1991, 229.

26. Bartoli, G.; Bosco, M.; Cimarelli, C.; Dalpozzo, R.; Guerra, M.; Palmieri, G.; J. Chem. Soc., Perkin Trans. 1 1992, 649.

27. (a) Bartoli, G.; Cimarelli, C.; Palmieri, G.; Bosco, M.; Dalpozzo, R Tetrahedron Lett. 1991, 32, 91. (b) Bartoli, G.; Bosco, M.; Cimarelli, C.; Dalpozzo, R.; De Munno, G.; Guercio G.; Palmieri, G.; J. Org,. Chem. 1992, 57, 6020. (c) Bartoli, G.; Bosco, M.; Cimarelli, C.; Dalpozzo, R.; Palmieri, G.; J. Chem. Soc., Perkin Trans. 1 1992, 2095. (d) Bartoli, G.; Bosco, M.; Cimarelli, C.; Dalpozzo, R.; Palmieri, G.; Tetrahedron 1993, 49, 2521. (e) Bartoli, G.; Bosco, M.; Cimarelli, C.; Dalpozzo, R.; Guercio, G.; Palmieri, G. J. Chem. Soc.Perkin Trans. 1, 1993, 2081. (f) Cimarelli, C.; Palmieri, G.; Camalli M. Tetrahedron: Asymm. 1996, 7, 2099. (g) Cimarelli, C.; Palmieri, G.; Camalli M. Tetrahedron 1997, 53 (20), 6893.

28. Bartoli, G.; Cimarelli, C.; Palmieri, G.; Rafaiani, G. Tetrahedron: Asymm. 1992, 3, 719.

29. (a) Shibahara, S.; Kondo, S.; Maeda, K.; Umezawa, H. Ohno, M. J. Am. Chem. Soc. 1972, 94, 4353. (b) Wang, Y.-F.; Izawa, T. Kobayashi, S.; Ohno, M. J. Am. Chem. Soc. 1982, 104, 6465. (c) Hashiguchi, S.; Kawada, A.; Natsugari, H. J. Chem. Soc., Perkin Trans. 1 1991, 2435. (d) Knapp S. Chem. Rev. 1995, 95, 1859. (e) Kozikowski, A. P.; Chen, Y.-Y. J. Org. Chem. 1981, 46, 5248. (f) Jäger, V.; Schwab, W.; Buss, V. Angew. Chem. Int. Ed. 1981, 20, 601. (g) Hann, H.; Heitsch, H.; Rathmann, R.; Zimmermann, G.; Bormann, C.; Zähner, H.; König, W. A. Liebigs. Ann. Chem. 1987, 803. (h) Ohfune, H.; Acc. Chem. Res. 1992, 25, 360. (i) Davies, S. G.; Ichihara, O.; Tetrahedron Lett. 1999, 40, 9313.

30. Tramontini M.; Synthesis 1982, 605.

31. (a) Noyori, R.; Kitamura, M. Angew. Chem. Int,. Ed. 1991, 30, 49. (b) Soai, K.; Niwa, S. Chem Rev. 1992, 92, 833. (c) Knochel, P.; Singer, R. D. Chem. Rev. 1993, 93 2117. (d) Mukaiyama, T.; Soai, K.; Shimizu, H.; Suzuki, K. J. Am. Chem. Soc. 1979, 101, 1455. (e) Ognuni, M.; Omi, T. Tetrahedron Lett. 1984, 25, 2823.

32. Bartoli, G.; Cimarelli, C.; Palmieri, G. J. Chem. Soc, Perkin Trans 1 1994, 537. 
33. Bartoli, G.; Cupone. G.; Dal Pozzo, R.; De Nino, A.; Mariuolo, L.; Procopio, A.; Tagarelli, A.; Tetrahedron Lett. 2000, 43, 7441.

34. Nilsson, L. Acta Chem. Scand., Series B 1979, B33, 547.

35. SanMartin, R.; Martinez de Marigorta, E.; Dominguez, E. Tetrahedron 1994, 50, 2255.

36. Bartoli, G.; Cimarelli, C.; Marcantoni, E.; Palmieri, G.; Petrini, M. J. Org. Chem 1994, 59, 5328.

37. Cimarelli, C.; Palmieri, G.; Bartoli, G. Tetrahedron: Asymmetry 1994, 5, 1455.

38. Cimarelli, C.; Palmieri, G.; J. Org. Chem 1996, 61, 5557.

39. Cimarelli, C.; Palmieri, G.; Volpini, E. Synth. Commun. 2001, 31, 2943.

40. Harris, M. I. N. C.; Braga, A. C. H. J. Braz. Chem. Soc. 2004, 15 (6), 971.

41. Braga, A. C. H.; Harris, M. I. N. C. BR 9502467 A 19970826 Patent; CAN 128:243740.

42. Cimarelli, C.; Giuli, S.; Palmieri, G. unpublished results.

43. Cimarelli, C.; Palmieri, G.; Volpini, E.; unpublished results.

44. Cimarelli, C.; Palmieri, G. Eur. J. Org. Chem. in print.

45. (a) Calvet, S.; David, O.; Vanucci-Bacque, C.; Fargeau-Bellassoued, M.-C.; Lhommet, G.. Tetrahedron 2003, 59, 6333. (b) Haviari, G.; Celerier, J. P.; Petit, H.; Lhommet, G.; Gardette, D.; Gramain, J. C. Tetrahedron Lett. 1992, 33, 4311. (c) Blot, J.; Bardou, A.; Bellec, C.; Fargeau-Bellassoued, M.-C.; Celerier, J. P.; Lhommet, G.; Gardette, D.; Gramain, J.-C. Tetrahedron Lett. 1997, 38, 8511.

46. Calvet-Vitale, S.; Vanucci-Bacque, C.; Fargeau-Bellassoued, M.-C.; Lhommet, G. Tetrahedron 2005, 61, 7774.

47. Freville, S.; Delbecq, P.; Thuy, V. M.; Petit, H.; Celerier, J. P.; Lhommet, G Tetrahedron Lett. 2001, 42, 4609.

48. (a) David, O.; Blot, J.; Bellec, C.; Fargeau-Bellassoued, M.-C.; Haviari, G.; Celerier, J.-P.; Lhommet, G.; Gramain, J.-C.; Gardette, D. J. Org. Chem. 1999, 64 (9), 3122. (b) Celerier, J. P.; Haddad, M.; Saliou, C.; Lhommet, G.; Dhimane, H.; Pommelet, J. C.; Chuche, J. Tetrahedron 1989, 45, 6161.

49. Thank, G. V.; Celerier, J.-P.; Lhommet, G. Tetrahedron: Asymmetry 1996, 7, 2211.

50. Provot, O.; Celerier, J.-P.; Petit, H.; Lhommet, G.. J. Org. Chem. 1992, 57, 2163.

51. Matsumura, H.; Nozaki, Y.; Sunagawa, M. Chem. Pharm. Bull. 1994, 42, 2467.

52. De Risi, C.; Pollini, G.; Veronese, A. C.; Bertolasi, V. Tetrahedron Lett. 1999, 40, 6995. 